\title{
TECHNO-ECONOMIC APPROACHES TO ENVIRONMENTAL ACTIONS: \\ A CASE STUDY FOR THE ESTABLISHMENT OF A CENTRE FOR SUSTAINABLE DEVELOPMENT IN THE ISLAND OF RHODES
}

\author{
Assist.Prof.Dr.Persa Fokiali, University of the Aegean, persa@rhodes.aegean.gr \\ Prof.Dr.Rezan Tatlidil, Ege University, Faculty of Economics and Administrative \\ Sciences, Department of Business Administration, rezan.tatlidil@ege.edu.tr; \\ Loukas Moustakas, University of the Aegean. \\ Assoc.Prof.Dr.Yota Xanthakou, , University of the Aegean.
}

\begin{abstract}
For the economic world, the ever-increasing speed with which economic changes occur requires quick and safe responses that are aimed at increasing efficiency and competitiveness, while at the same time keeping business risk to a minimum. Under such conditions, decisions taken need to be backed by a thorough and convincing investigation of the issues involved, enabling clear conclusions to be drawn as to what course of action should ensue. By the way, the techno-economic study is a tool for exploring the feasibility, the technical characteristics, the cost and the viability of a decision (investment, project, action).

The object of this study is to examine the potential for using the classic approach of techno-economic studies as a methodological tool in planning projects and actions related to the environment and sustainable development. The main hypothesis supported in this study is that, the application of the techno-economic study can be standardized the decision-making process and this is highly useful in decision-making. The research analysis has shown that the techno-economic study is an adequate tool for making an integrated approach to actions/investment/projects of environmental content. However, this study has also shown that the techno-economic approach is adequate without requiring major deviations from the specifications, conventions and standard forms on which it is based in the case of business-oriented applications.
\end{abstract}

Key Words: Techno-Economic Approaches, Sustainable Development 
Persa FOKIALI, Rezan TATLIDIL,

Loukas MOUSTAKAS and Yota XANTHAKOU

\section{INTRODUCTION}

The object of this study is to examine the potential for using the classic approach of techno-economic studies as a methodological tool in planning projects and actions related to the environment and sustainable development. The technical character of such studies and their spotlight on terms concerning economic viability, accounting costs and profits make them attractive approaches in the process of making financially sound decisions on the part of profit maximizing enterprises. The business world trusts such approaches and uses them widely. On the other hand, the use of such approaches for environmental purposes is limited. A codification of environmental cost and benefit drawn up purely in accounting terms is rare and, if applied unadjusted, could lead to negative economic forecasts of results.

This study states that, under appropriate adjustments, the application of business oriented techno-economic approaches in environmental projects and actions can create a link between those seeking to make profit and those who hold idealistic notions about environmental protection. Such a link seems to be a valuable challenge in a world in which the two parties seem to work and think on the same issue independently of each other.

Within this framework, this study is developed in two parts: the first part is an attempt to examine whether it is possible to adapt the techno-economic study to activities with an environmental content. The second part is an actual case study presenting the techno-economic approach to a proposed new sustainable structure, namely a Municipal Centre for Sustainable Development (MCSD) on the island of Rhodes.

\section{THE CONCEPT OF THE TECHNO-ECONOMIC STUDY}

For the economic world, the ever-increasing speed with which economic changes occur requires quick and safe responses that are aimed at boosting efficiency and competitiveness, while at the same time keeping business risk to a minimum. Under such conditions, decisions taken need to be backed by a thorough and convincing investigation of the issues involved, enabling clear conclusions to be drawn as to what course of action should ensue. One of the most widely accepted approaches to the decision-making process entails an integrated analysis of the problem during which opportunities, risks and peculiarities are identified, different scenarios are described and, by using strict criteria of selection and looking at them from various viewpoints, final decisions are made on whether to carry out the exercise in reality (Hanford 1972). The techno-economic study is an integrated description of this approach to financial decision making.

The techno-economic study is a tool for exploring the feasibility, the technical characteristics, the cost and the viability of a decision (investment, project, 
TECHNO-ECONOMIC APPROACHES TO ENVIRONMENTAL ACTIONS: A CASE STUDY FOR THE ESTABLISHMENT OF A

CENTRE FOR SUSTAINABLE DEVELOPMENT IN THE ISLAND OF RHODES action). Theoretically, this approach combines the academic investigation to an issue with the practical decision-making process with regard to the same issue. The academic part refers to the invoking of theoretical arguments supporting or rejecting a decision. The practical part refers to the fact that the complete and well-developed argument should result in clear conclusions for or against the decision, as well as the "who" does, "where", "how", "why", "when", "at what cost" the project will be carried out as well as to "what the anticipated effects will be". The techno-economic study should lead to clear and explicit positions of a "yes" or "no" type, hence the frequently encountered conclusion of many academic projects for the need for further investigation of the matter has no place in such a study.

It should be underlined that in simple everyday human actions, reasoned analyses, such as those catalogued in a techno-economic study, are often performed, usually in an informal way to identify the most advantageous or financially sound options. These are the procurement of goods, a refurbishment project or a journey all require decisions to be taken after certain thought processes of techno-economic nature. Moreover, in the daily operation of modern businesses, many decisions are taken, without adherence to any particular set of rules or rationale. In this case, the argument is that it is difficult and sometimes disappointing, to put hedges in an investor's visions. However, everybody agrees that it is better for any erroneous decisions to be prevented while still "on paper" than later on, in the production stages, with disastrous results (Gypton, 2002). This is similar to what Lewis (1998) claims saying, "things are achieved not at the end but at the beginning".

The main hypothesis supported in this study is that, prompted by the application of the techno-economic study, the decision-making process can be standardized and this is highly helpful in decision-making. Furthermore, taking for granted that environmental actions in favor of sustainable development are either profit making in the long run or, in any case, viable if social benefits are added to any economic returns on them. It may be argued that it is worthwhile to use techno-economic studies appropriately adjusted to makedecisions concerning environmental actions, investments and projects that promote sustainable development.

\section{THE CONCEPTUAL DIMENSIONS OF A TECHNO- ECONOMIC STUDY}

A techno-economic study is one of the tools available in decision-making. Since it is not the only one, it seems necessary to define it within the range of similar tools and more specifically in comparison with to other two the most important tools, namely the feasibility study and the business plan.

In the international bibliography, the term 'techno-economic study' and the term 'feasibility study' have a similar and in some cases tautological mission ${ }^{1}$. The 
Persa FOKIALI, Rezan TATLIDIL,

Loukas MOUSTAKAS and Yota XANTHAKOU

term 'feasibility study' is used internationally to mean the framework of a modular study/report comprising several separate supporting studies (economic, fiscal, technical, market, planning, etc.) (Gypton, 2002), all centered on investigating the feasibility of the action or project (Karvounis, 2000, and Milioti, 1992).

Karvounis (2002), maintains that the term 'feasibility study' does not adequately convey what the study seeks to convey. Certainly, there is considerable overlap between the concept of feasibility and the content of a techno-economic approach in decision making. There is however, a disagreement on whether this overlap leads in tautology or not. On the one hand, it is true that the term 'feasible' characterises any decision that can be implemented according to certain criteria but not necessarily the best one. In this sense, a feasibility study can be considered as a more general tool than the techno-economic study. On the other hand, if the feasibility study is a 'study of the expedient', as Karvounis argues, then it endeavours to prove to what extent it would be expedient to implement the project. Following on from this line of thinking, Burke (2002) claims that a feasibility study is not carried out merely in order to substantiate the expediency of a project, but also to prove that making financial resources available for such an investment would be the most advantageous option. In this latter sense, the feasibility study can be considered as coinciding with the techno-economic study.

In this context, Heldman (2003) proposes is a kind of compromise between these two viewpoints, as he maintains that a feasibility study is a preliminary study investigating the performance and viability of the project, together with the potential for its implementation. To the extent that the goals set in a feasibility study are the "S.M.A.R.T." goals (the acronym of "Specific, Measurable, Accurate/Agreed, Realistic and Time-bound", then the feasibility study coincides with the techno-economic study. In accordance with the requirements of a techno-economic study, the goals should first be clear and concise (Specific). They should be able to be measured so that they can be monitored by the mechanism as indicators (Measurable). Precision and acceptance/agreement (Accurate/Agreed) constitute another requirement that will relieve the organisation of a number of headaches during the next few stages. If the goals are not practicable (Realistic), it is quite likely they will put the programme itself at risk, "exhausting" and frustrating the study group to no avail. Finally, the setting of goals should be conducted within the context of the detailed timetable for the investment plan (Time-bound).

Many researchers investigating the theoretical foundation of comparable studies to the techno-economic study, such as Meredith \& Samuel (1995) and Gypton \& Shillabeer (2003), make a distinction between a macro-feasibility study and a micro-feasibility study, considering the latter to be simply the detailed report of the former (Meredith \& Samuel, 1995). In this case, the combination of the two forms the techno-economicapproach. 


\section{TECHNO-ECONOMIC APPROACHES TO ENVIRONMENTAL ACTIONS A CASE STUDY FOR THE ESTABLISHMENT OF A \\ CENTRE FOR SUSTAINABLE DEVELOPMENT IN THE ISLAND OF RHODES}

In any case, if not a tautology, the term 'feasibility study' at least denotes one of the main pillars on which the techno-economic study is based, namely the part that contains all the theoretical reasons and arguments why the decision should be made or rejected. In this sense, the term 'techno-economic study' goes one step further compared with the term 'feasibility study' and is used to denote the integrated, modular study that contains all the steps in decision making.

Finally, the term 'techno-economic study' should be distinguished from the term 'business plan' which is a much wider, lengthy and highly accurate study, that covers any detail on the subject, giving a highly accurate time plan and operation plan with respect to the project under consideration.

\section{STRUCTURE OF TECHNO-ECONOMIC STUDY}

The structure of a techno-economic study follows the rational steps in decisionmaking. Thus, the classic stages followed by an investment idea from the moment of conception until its completion (Lewis, 1998) are:

- Identification of the problem, original idea, transformation of this original idea into a proposal, setting of goals and strategy development,

- Analysis, i.e. detailed examination of the issue from a number of viewpoints,

- Synthesis, i.e. plan for implementing the proposed project, containing details on what has to be done, by whom, adopting what approach, working to what timetable and at what cost,

- Implementation,

- Evaluation of results.

Given the above one general structure ${ }^{2}$ fortechno-economic studies that is in widespread use comprises the following sections (Karvounis, 2000 and Milioti, 1992):

- General information on the identity of the subject;

- Modular analysis containing a number of supporting studies;

- Synthesis which forms the main body of the study ${ }^{3}$ and contains in a certain detail the implementation plan, the timetable, the budget and the estimated results;

- Bibliography and appendices.

Although there is considerable agreement over the above general structure of the techno-economic study, it should be noted that there is no single approach or rigidly defined model that would fit the bill for every type, size and category of investment plan (Karvounis, 2000). In this sense, appropriate adjustments are necessary, so that the techno-economic studies for a specific project meets the project's requirements. 
Persa FOKIALI, Rezan TATLIDIL,

Loukas MOUSTAKAS and Yota XANTHAKOU

\section{THE STRUCTURE OF A TECHNO-ECONOMICSTUDY ADAPTED FOR ENVIRONMENTAL ACTIONS}

Within the framework of the above general structure it is interesting to examine what adaptations should be make to develop an outline for a techno-economic study that fits in an environmental action/investment/project.

The basic criteria for such an adaptation are the following:

- Completeness so that the study leads to final decisions;

- Generality so that it is relevant to a large range of environmental actions;

- Accuracy and technicality so that it defines explicitly the action under examination;

- Neutrality, so that it convinces both, environmentalists and nonenvironmentalists.

\subsection{Section I. General Information on the Identity of the Subject}

This should comprise:

(a) a title page with the name of the agent or body on whose behalf the study is being conducted, the researcher's name and the date,

(b) a table of contents,

(c) an executive summary:

It is necessary to include in the first section a clear but concise presentation of the various modules comprising the study, the needs that brought it about, the total cost and the completion date (Heldman, 2004). The purpose of such a synopsis is to facilitate presentation. It provides a rough description of the investment figures/data and presents all the conclusions drawn and proposals made at the end of each section of the study. Together with these findings, the summary should clearly demonstrate the reliability of the facts and figures used in respect of the business in question, its revenue and expenditure, technological choices and margin of error in forecasts relating to the market, products and services provided.

\subsection{Section II. Supporting Studies}

The typical supporting studies for an environmental action/investment/project are the following: 
TECHNO-ECONOMICAPPROACHES TO ENVIRONMENTALACTIONS:

A CASE STUDY FOR THE ESTABLISHMENT OF A

CENT'RE FOR SUSTAINABLE DEVELOPMENT IN T'HE ISLAND OF RHODES

\subsubsection{Macroscopic Feasibility Study}

Generally, a macroscopic feasibility study or macro-feasibility study, within the framework of a techno-economic study, is a report that contains the reasons why the investment should be made in the area in question and underthe conditions prevailing. A macro-feasibility study merely responds to the question 'why should (or should not) this particular action take place in this particular place, at this particular time and under these particular conditions'.

In the specific case of environmental projects and actions, the macro-feasibility study examines macroscopically, without measuring explicitly, the repercussions of a specific action on the economic, social, cultural and natural environment, especially its effect on wages and income, employment and development at both regional and national level, natural, social and cultural resources etc. If the investment is not deemed feasible at this stage, then there is no point in continuing with further details or in setting out the demands and constraints in its implementation.

\subsubsection{Study of Environmental Needs}

This usually constitutes part of a macro-feasibility study. However, in the case of activities with an environmental content, it is useful to separate the environmental reasons why a particular action is necessary and to elaborate in more detail on this. Such a study could comprise the following:

- Theoretical mainstreaming analysis of the context to the activity in question belongs (e.g. reference to environmental conferences' declarations and agendas, the institutional framework on an international, national and local level etc).

- Analysis of the existing situation gives that rise to the need for action.

- References to other studies indicate that the need for environmental intervention.

- Field studies carried out specifically for proving the need for environmental intervention (e.g. research on the environmental awareness of target groups prior to the implementation of environmental education activities).

\subsubsection{Environmental Impact Assessment Study}

The environmental impact assessment study (EIAS) is an essential component in the granting of consent for implementation of a project. In the case of activities of environmental interest, this study should contain analysis in two differentdimensions ${ }^{4}$ - the ecocentric and the anthropocentric (Georgopoulos, 2002). The ecocentric approach sees the natural environment as undergoing intense pressure from all human activities. The anthropocentric outlook, on the 
Persa FOKIALI, Rezan TATLIDIL,

Loukas MOUSTAKAS and Yota XANTHAKOU

other hand, views the natural environment as an impediment standing in the way of any investment activity by imposing constraints, whether these be of a practical or a regulatory nature.

Within the framework of the techno-economic study, these two approaches are portrayed in a report that analyses these issues and proposes ways of dealing with the added load on the environment that will be caused by implementation of this action (Cooper \& Ebin, 2004).

\subsubsection{Market Research and Study of the Marketing Strategy}

Market research in general is a procedure aimed at obtaining all the necessary information concerning the 'market' in which a business operates. It is a painstaking exercise involving data, statistics and mathematics (Hanford, 1972), which will reveal whether the proposed action can be incorporated into and take up a competitive position in this market ${ }^{5}$. The market research investigates the proposed action in relation to other establishments with which the action or plan will either compete with or complement. Fundamental questions such a study should seek to answer are the following: (a) up to what extent the competitive environment allows the introduction of an additional activity (b) what is the role quantitative and qualitative - that this activity will play (c) up to what extent there are existing structures in support of the new activity.

In the case of actions with an environmental content, such a market research, (Kotler, 1996), focuses on issues such as the existence of other actions that work complementing or competing the one under examination and the availability of the appropriate institutional, educational and social environment in support to the proposed environmental action under examination.

The marketing strategy, which is business oriented, aims to the identification of competition policies and the development of ways for attracting clients (Lewis, 1998). The strategy consists of a series of tactics based on a package of four axes that, according to Kotler (1996), are summed up the well known 'four Ps' i.e. Product, Price, Promotion and Place ${ }^{6}$.

In the case of environment-related actions, the 'product' is of an environmental content and in many cases intangible (e.g., environmental education and training programmes could be the outcome of an environmental project). If the product is sold, there is certainly a 'price' for it and the relevant tactic refers to investigating the criteria and rules of an attractive pricing. There are cases however, in which the product is offered free. In these cases, the price should be substituted by another factor, such as the estimated benefits from acquiring it. Quantification of such an estimate helps as an input in the analysis of the project's viability. The initiatives related to the management of information and publicity for the activities form the 'promotion' tactics. Lastly, the 'place' option 
TECHNO-ECONOMICAPPROACHES TO ENVIRONMENTALACTIONS: A CASE STUDY FOR THE ESTABLISHMENT OF A CENTRE FOR SUSTAINABLE DEVELOPMENT IN THE ISLAND OF RHODES refers to the accessibility and appeal of the site where the activities are to take place.

\subsubsection{Study of the Production Process and Operation Requirements}

Having identified the market and the marketing strategy, it is usually necessary in a techno-economic study, to determine the production process (flow) that will transform the available inputs into final products (Gypton \& Shillabeer, 2003). For such a purpose, it is necessary to identify (a) the installations, machinery, other equipment and know-how required for the project's implementation and (b) the raw materials, manpower, energy and other inputs required for its operation. The corresponding options are determined by the nature of the product itself, the technology required, the local conditions and manpower resources. It will thus be clear that analysis at this stage includes matters relating to technical issues, management and administration, the socio-political set-up and the economic environment (Cooper \& Ebin, 2004).

The procedure for determining the installations needed entails a study of the specifications and of requirements in terms of buildings and infrastructure work. In the case of actions with an environmental content, the uniqueness of the circumstances often requires the production of specifications relating to the installations and production flow.

The machinery and equipment selection procedure (Gypton, 2002) calls for; (a) an examination of the specifications for machinery and plant in relation to needs, (b) an estimation of the cost including taxes, import duties, transportation and withdrawal costs, (c) a survey of the adequacy of alternative and specialised auxiliary personnel and (d) an inspection of the relevant legislation, regulations and models. Information can be crosschecked with data from other, similar, production plants or from special databases (Cooper \& Ebin, 2004).

The procedure for determining the know-how needed involves finding (a) personnel willing to pass on technical knowledge and expertise and (b) employees willing to undergo training. For activities of an environmental content, knowledge of environmental issues and environmental awareness form an important part of the required expertise.

The procedure for locating raw materials and other supplies essential to the uninterrupted operation of the action is important, since there is a direct interdependence and inter-reaction between raw materials and supplies with most of the parameters that affect the business plan (Duncan, 1996). The choice of raw materials and other supplies is also dependent on and affected by the enterprise's technical requirements. In the case of actions with an environmental content, particular attention should be paid to the environmental dimension of the raw materials to avoid causing depletion of sensitive resources and pollution (Gypton \& Shillabeer, 2003). Recycled and renewable resources 
Persa FOKIALI, Rezan TATLIDIL,

Loukas MOUSTAKAS and Yota XANTHAKOU

and materials should be selected if possible, together with materials that have no adverse repercussions on health and the environment.

There is also a need to determine both existing manpower and the human resources required to ensure the smooth operation of the proposed activity after its implementation. This is a key factor, because engagement of the right personnel - the cornerstone of the investment plan with proper management, makes the difference between success and failure, overthrowing all the plans and forecasts of the pre-investment stage (Lewis, 1998). The objective is to determine the overall needs in human resources, both quantitative and qualitative.

On the basis of the prepared organogram, detailed job descriptions should be drawn up in order to identify the qualifications needed, along with job descriptions for every administrative unit and every department. And estimate the personnel costs per directorate, department and category of expenditure, choice of procedure to be used in staff selection, preparation of a reception programme for new employees and of a staff training programme, establishment of personnel policy and finally the engagement of staff (Karvounis, 2000). For actions of environmental content, it is necessary that the personnel should have a strong background in environmental issues, else environmental education and training should be provided, as part of the action.

\subsubsection{Pilot Implementation of the Proposed Production Process and Final Product}

Unlike activities, relating to the production of well-known, mass-produced goods or services, the production process and the final product of an environmental action is often innovative and unique. This creates the need for making pilot studies for the implementation of production, thus providing a full description and evaluation of the final product. In this context, the following may be incorporated into the techno-economic study:

- Studies of alternative production processes with an evaluation of their effectiveness/ efficiency.

- Simulations the selected production process and/or pilot small-scale implementation of the action. The results of such applications can be compared with those of similar applications available in the relevant field.

Where environment-related actions are concerned, the relevant activities should be fully described and evaluated. For example a modular environmental education and training programme addressed to children should be described and evaluated in terms of contents, target group, size of class, duration and intensiveness, educational material and teaching approach, all these being considered as the constituents of the production process. Furthermore, a pilot 
TECHNO-ECONOMIC APPROACHES TO ENVIRONMENTAL ACTIONS: A CASE STUDY FOR THE ESTABLISHMENT OF A CENT'RE FOR SUSTAINABLE DEVELOPMENT IN T'HE ISLAND OF RHODES study of a small-scale application in one of the modules can be attempted, in order to ascertain the effectiveness of the process.

\subsection{Section III. Main Body of the Study}

\subsubsection{Site Study for Location of Installations}

After establishing in the preceding studies precisely what is to be constructed and what the investment plan in question requires, the first part of the main body of the study comprises a description of the location (Cooper \& Ebin, 2004). The appropriate procedure is to identify a number of geographic areas that satisfy the requirements and then pinpoint possible areas within them. Carrying out an analysis and giving a rating to the prerequisites produces an evaluation of the various geographic areas based on which they can be ranked in order of priority. The study group assigned to carry out seriously take into account a number of criteria that could put the investment at risk, such as ownership disputes, land use zoning, prospects for both the investment and the area, legislation, infrastructure - networks, transportation - social factors, such as the existence of schools, churches, etc., security, whether privacy is required, etc. (Cooper \& Ebin, 2004).

It should be noted, however, many times the location is already available beforehand and the analysis focuses on its characteristics, its appropriateness and possible interventions for improvements.

\subsubsection{Description of Cost Categories, Timetable and Budget for the Proposed Action in Respect of the Whole Project and for Each Sub-Project Separately}

This step is related to the above-mentioned 'study of the production process and operation requirements'. It is developed along two axes. In the first, there is a short description of the basic categories and sub-categories of the required inputs, followed by a table that contains the estimated budget for each of them. This leads to a presentation in separate tables of the estimated cost of installations, machinery, equipment, know how, etc. which are summed up in a final table that contains the overall budget of the project up to the point at which this is ready to operate.

The second axis now contains the development of a realistic time programme of the project's implementation. For this purpose, the project under examination is divided into sub-projects or stages of specific duration depending on the peculiarities of each sub-project. It is necessary to describe the tasks of each stage and to draw up accordingly a timetable of the various actions together with the relevant expenditure. This final schedule should be incorporated into 
Persa FOKIALI, Rezan TATLIDIL,

Loukas MOUSTAKAS and Yota XANTHAKOU

the overall programme (Duncan, 1996). The expenditure upon completion of the timetable coincides with the total budget of the project.

\subsubsection{Financial Investment Analysis}

From a fiscal and economic point of view, investment is defined as a long-term commitment of financial resources aimed at the production and receipt of clear profit in the future (Karvounis, 2000). This is the stage when financing sources are investigated concerning the proposed action.

In the business world, the classic sources of financing are, as a rule, private capital, loan capital and grants/ subsidies. For actions with an environmental content, the same sources apply. However, in environmental actions special attention should be paid to the relationship between the sources and the viability of the action. The fact that actions of this nature are not profitable in strict accounting terms advocates the avoidance of loans as a means of financing, since a loan creates an increase in the operating cost through interest payments.

\subsubsection{Viability Forecast}

At this point, it is necessary to distinguish between investment plans that have a tangible product capable of being evaluated in purely financial terms, and those whose final product is intangible, when the feasibility approach cannot be confined to a narrow economic framework. In both cases, however, a costbenefit analysis should be carried out in order to determine whether the project is viable from an economic viewpoint.

Analysis of a project's viability is based in a simple guiding principle: when the revenue from the distribution of the product is greater than the expenditure for its production, then by and large the action is viable. In such a purely financial approach, economic viability can be measured as the difference between profit and loss: when the profits from a project exceed total losses, then it is deemed viable from an economic point of view (Begg, 1998). However, one can rely on a variety of criteria for assessing viability, among which the following are worth mentioning:

- Monitoring of willingness to pay, perceives and evaluates a product from the point of view of demand, i.e. the amount customers are willing to pay for it;

- Hicks-Kaldor Test, which makes a more realistic approach to the costbenefit dyad by stating that "for an investment to be beneficial the total profits should exceed total losses", in which case those who gain from the project should reimburse those who lose;

- Pareto Criterion that states, "The project should improve the situation for some people without making it worse for others". 
TECHNO-ECONOMIC APPROACHES TO ENVIRONMENTAL ACTIONS: A CASE STUDY FOR THE ESTABLISHMENT OF A CENT'RE FOR SUSTAINABLE DEVELOPMENT IN THE ISLAND OF RHODES

Where actions have an environmental content, the profit should be seen as a social rather than a financial benefit. Of course, evaluation of social benefit is not an easy matter, mainly because there is no standardised procedure laid down for this task. However, it is essential that such an evaluation be carried out individually for each separate case and preferably this attempt should lead to a quantification of the social benefit.

\subsubsection{Evaluation of the Results and Final Proposal}

This section contains the conclusions of all the modular studies as well as of the main body of the techno-economic study leading to the final verdict for or against implementation of the action in question.

\subsection{Section VI. Bibliography and Appendices}

The sources of data used and any additional information such as tables, calculations, norms, photographs, plans, diagrams, measurements, technical specifications, etc., are contained in this section.

\section{SHORT PRESENTATION OF A TECHNO-ECONOMIC APPROACH TO THE ESTABLISHMENT OF A MUNICIPAL CENTRE FOR SUSTAINABLE DEVELOPMENT AT THE MUNICIPALITY OF PETALOUDES, RHODES}

Based on the content and structure of a techno-economic study, this section is devoted to a summarised presentation of the techno-economic approach to an action of environmental content. The action under examination refers to the establishment of a Municipal Centre for Sustainable Development (MCSD) that has been proposed for the Municipality of Petaloudes, on the island of Rhodes.

\subsection{Section I. General Information On The Identity Of The Proposed MCSD}

The content of the proposal

The study in question proposes the establishment of a new and innovative venture of environmental interest, called the Municipal Centre for Sustainable Development (MCSD). This is an institution aiming to become a model regional environmentalinstitution and the heart of the Municipality of Petaloudes' environmental policy.

MCSD is a highly specialised, groundbreaking action with far-reaching potential that can play a major role in the local community. The special and innovative nature of the investment has two main thrusts: the possibility of providing good, 
Persa FOKIALI, Rezan TATLIDIL,

Loukas MOUSTAKAS and Yota XANTHAKOU

scientifically based, informal and lifelong environmental education, and the amalgamation of three representative environmental structures, namely the Department of Environmental Education, the Workshop for Measuring Environmental Indicators and the Environment Office.

With regard to its physical dimension, this investment programme could be described as a small new unit in the field of the environment and education. The investment is labour intensive, with local scope and low investment risk, and has a strong social mission.

Name of agent: Municipality of Petaloudes ${ }^{7}$

Legal status: Local Authority Organisation

Information about the agent:

The Municipality of Petaloudes, geographically and administratively part of the Province of Rhodes and the union of six previously separate communities (Kremastis, Paradisi, Theologos, Pastida, Maritsa and Damatria) formed the Prefecture of the Dodecanese. That now constitutes the area's administrative districts.

The Municipality lies in the northwest corner of the island of Rhodes, at a distance of $10 \mathrm{~km}$ from the City of Rhodes. It covers an area of $893 \mathrm{~km} 2$, with a great deal of geomorphological variety. Most of the area is mountainous. On its administrative borders lies the Valley of the Butterflies, an area of outstanding natural beauty renowned for its ecological diversity (Tsetsis, 2000).

The environment was high on the Municipality's list of priorities. This is so on the one hand because of the existence of the protected habitat of the Valley of the Butterflies and on the other due to a number of environmentally unfriendly activities such as a main local station of the national electricity provider8, the Diagoras international airport and the big hotel complexes at Theologos.

The proposed MCSD is expected to contribute in the promotion of a sustainable development strategy by providing solutions to the environmental problems and conflicts, increasing environmental awareness and by promoting environmentally friendly planning.

\subsection{Section II. Modular supporting Studies for the MCSD.}

\subsubsection{Macroscopic Feasibility Study}

The MCSD is proposed in order to promote sustainable development at a local level. As already stated the area's identity is characterised by environmental uniqueness and pressures, hence it is a place where sustainable development 
TECHNO-ECONOMIC APPROACHES TO ENVIRONMENTAL ACTIONS: A CASE STUDY FOR THE ESTABLISHMENT OF A CENTRE FOR SUSTAINABLE DEVELOPMENT IN THE ISLAND OF RHODES strategy provides a well-accepted principle. Directly or indirectly, the MCSD is expected to find ways to plan and implement such a sustainable development strategy in an attempt to promote development while protecting the environment.

Apart from that, the MCSD has a broad-ranging package of more specific goals that justify the proposition for its establishment. The package includes educational, environmental, and social goals, which could be divided into two categories, direct and indirect. The direct goals entail mainly those of an educational and environmental nature, while the indirect goals have a social content.

Looking at educational goals, a cutting-edge development has been the potential for a systematic and practical application of the ongoing character of Environmental Education9 which, in Greece, by the existing structures, cannot been considered adequate. The proposed MCSD is expected to implement actions that include the training of suitable instructors, the development and production of educational material, the establishment of a library and support for environmental education in schools. The flexibility of its structure and the carefully devised actions that are totally in line with the principles of Environmental Education, complete the first "pillar" of activities aimed at creating "environmentally responsible citizens, citizens with an ecological education and awareness" (Flogaïti, 1998).

The second pillar is aimed at "shielding" the local population from environmental problems. Provision will be made to record and study such problems at a local level and carry out sustainable planning, on the one hand, and regular measurements of, and research into, burning issues on the other. This practice will contribute to alerting the local population to environmental matters, increase their readiness for involvement and create up-to-date databanks with environmental indicators.

The third of these pillars, the MCSD's social goals, refers to the role of the Centre as a vital link between environment policy and the local community. The aim for the MCSD is not to act from within a hermetically sealed protective "shell"; on the contrary, the organisation is expected to be in constant communication and interaction with the outside world. To this end, a committee comprising members of the local community is expected to strengthen the MCSD's advisory role in the community, undertaking also other tasks such as the coordination and implementation of environmental activities and awareness campaigns aimed at mobilising the local population.

In addition, there are also a number of indirect goals and spin-offs from the operation of the MCSD, such as:

- Support of the region's development activities by providing valuable information, studies and proposals, as well as by offering its seminar 
Persa FOKIALI, Rezan TATLIDIL,

Loukas MOUSTAKAS and Yota XANTHAKOU

hall, library and laboratories to accommodate other municipal programmes and needs.

- Provision of recreational opportunities for young people, especially during the winter months, when such opportunities are scarce.

- Job creation for both specialised and unskilled personnel.

- Evaluation of inactive resources through the utilisation of public buildings that have remained empty/unused for many years.

- Boost for local tourism with the operation of a "green" campsite that will be open to people of all ages at certain times of year.

\subsubsection{Study of Environmental Needs}

In order to ascertain the need for the environmental action in question, the following were steps carried out:

With regard to environmental issues, research to ascertain the degree of awareness, knowledge, attitudes and perceptions into the student population among schoolchildren. The research was conducted using a sample of pupils from Rhodes 2nd Senior High School in December 2004 and pupils from the same class in the Municipality of Petaloudes in May 2005. The main conclusion drawn was that students have little knowledge on environmental issues and the knowledge they do possess in this field is not translated satisfactorily into environmentally friendly attitudes and practices.

Examination of local environmental matters revealed the existence of a number of burning issues.

Examination of the contents of secondary school analytical programme revealed that students complete their education without having received adequate information or training in environmental issues.

These studies highlighted the need to set up a structure that would continue the process of Environmental Education based on life-long learning schemes.

\subsubsection{Market Research}

Product of the action was deemed the MCSD itself and its activities, encapsulated in its informal Environmental Education programme, the Environment Office with its chiefly advisory role, the Laboratory for the measurement of environmental indicators and the opportunity for alternative forms of tourism. The product's innovative quality lies in its multifaceted approach to environmental education issues. 
TECHNO-ECONOMIC APPROACHES TO ENVIRONMENTAL ACTIONS: A CASE STUDY FOR THE ESTABLISHMENT OF A

CENTRE FOR SUSTAINABLE DEVELOPMENT IN THE ISLAND OF RHODES

Demand can be viewed from two perspectives. One view is that demand is proportionate to the deterioration of environmental issues and the build-up of deadlock situations, impasses, etc. The second standpoint approaches the question from another angle, claiming that what is needed for the operation of the MCSD is not an existing "clientele" calling for its establishment, since its purpose is to reach and alert those members of the local population who possibly are not even aware they need it.

Complementarily with other institutions: There are already a number of environmental structures within the Municipality of Petaloudes, each of which is part of an "articulated model" for the exercise of environmental policy.

Competition, where environmental issues are concerned, do not exist, in the sense that any action that protects environment, whoever it is performed by, is desirable if it succeeds in making even one citizen more environmentally aware and in mobilising him to be proactive in the field of environmental protection. Besides, the Centre does not act in any competitive manner that would be detrimental to another institution. The institution most likely to be affected in the area is the Centre for Environmental Education (CEE), which could lodge an appeal, mainly because CEE is already monitoring some environmental parameters. However, the proposed MCSD addresses age groups with little or no access to the CEE, is not seeking to replace laboratories furnished with accurate equipment. Its aim is to be able, with suitable equipment, to monitor the readings for some important environmental indicators (even with slight deviations) and thereby be in a position to alert the relevant Local Authority services to any problems in good time so they can take the necessary action. It argued that the MCSD is not a substitute for existing structures but serves to complement them by organising a variety of activities that will contribute to the upgrading of environmental institutions.

The most important those could orient competition believed that their interests are threatened by the adoption of a sustainable development strategy. However, the MCSD's role is not to fight against them but rather to help them realise that their long-term interests coincide with the sustainable development principles.

However, given the inadequate environmental awareness, the successful operation of the MCSD is expected to be a difficult task. Since society functions based on consumer priorities and are unused to such structures, its introduction will require a major information and awareness campaign. To this end, a large number of activities should be planned, including suitable publications in the media, the preparation and distribution of information leaflets, the briefing of target groups, schoolchildren and teachers in the Municipality of Petaloudes and construction of a website.

The impact of the new structure on the local community is expected to be favourable and the investment plan will be able to meet the needs of all citizens. 
Persa FOKIALI, Rezan TATLIDIL,

Loukas MOUSTAKAS and Yota XANTHAKOU

\subsection{Section III. Main Body of the Study}

\subsubsection{Site Location Selection}

It is proposed that the building should be erected in the Municipality of Petaloudes in the district of Kremasti, on an approximately 0.5 Ha plot owned by the Municipality. The reasons for choosing this particular municipality have already been set out in the chapter referring to the agent for the project. The choice of Kremasti was made because that is where the municipal headquarters are located and because it has the largest population. This choice should ensure municipal support for the new structure and critical mass with regard to the population groups to whom its establishment is addressed. This is thought to be essential for a pilot programme in whose implementation the risk of malfunction because of external factors must be kept to a minimum. Another reason operating in favour of the choice of Kremasti for the Workshop's location is the existence of the University of the Aegean's Postgraduate Department of Environmental Education, the operation of which is expected to have both a direct and an indirect impact on the Workshop.

The proposed choice of site is the consequence of a number of factors, such as its central location, its accessibility, the existence of other undeveloped sites, its proximity to the sea, etc.

6.3.2. Description of Cost Categories, Timetable and Budget ${ }^{10}$ for the Proposed Action in Respect of the Whole Project and for Each Sub-Project Separately

The installations required comprise of the following:

- Premises, specifically a building with a total area of $190 \mathrm{~m}^{2}$, which will include the library, reading-room, laboratory, computer room and seminar hall

- Infrastructure work, including some tasks that are environmentally friendly such as a photovoltaic system for using solar energy and automated energy management

- Computers and other equipment

- Landscaping of surrounding area

- Special facilities for the campsite area.

\section{Premises}

The building of the MCSD is a metal-framed construction that includes a reception area, secretarial accommodation, administration office, library and 
TECHNO-ECONOMIC APPROACHES TO ENVIRONMENTAL ACTIONS: A CASE STUDY FOR THE ESTABLISHMENT OF A CENTRE FOR SUSTAINABLE DEVELOPMENT IN THE ISLAND OF RHODES reading-room, workshop, computer room, seminar hall, storeroom and auxiliary rooms outdoor areas and campsite.

The building consists of altogether ten separate areas, which meet the needs of the MCSD and contribute to the attainment of the goals set. Details of these areas are as follows:

As shown in Table 1, the specifications and estimated costs of the building are expected.

Table 1: Buildings

\begin{tabular}{|l|r|}
\hline \multicolumn{1}{|c|}{ TYPE } & \multicolumn{1}{c|}{ COST } \\
\hline BASE 250 m ${ }^{2}$ & 37,500 \\
\hline PREFABRICATED STRUCTURE $190 \mathrm{~m}^{2}$ & 60,800 \\
\hline USUAL PLUMBING INSTALLATIONS & 2,000 \\
\hline USUAL DRAINAGE INSTALLATIONS & 3,000 \\
\hline HIGH VOLTAGE ELECTRICITY SUPPLY & 1,500 \\
\hline LOW VOLTAGE ELECTRICITY SUPPLY & 2,000 \\
\hline TOTAL BUILDING EXPENDITURE & 106,800 \\
\hline
\end{tabular}

\section{Infrastructure}

Since it was thought that the whole assignment should be an example of an environmentally friendly undertaking, it was deemed expedient that some of the infrastructure work should be of a sustainable design. A number of environmentally friendly solutions were chosen, even though they increased the construction costs, for the following reasons:

1. They are semiologically and symbolically appropriate to an environmental installation.

2. They will keep down future operational costs.

3. There are number of programmes that subsidise such solutions.

The cost to be shouldered by the body carrying out the action will therefore be reduced by the amount of the subsidy.

The study proposes that particular attention should be paid to the levels of toxicity and the behaviour in high temperatures of the construction and insulation materials used.

The installation of a photovoltaic panel is also proposed to meet all the Environmental Workshop's energy requirements, in conjunction with a "smart" system of energy management, which is able to detect movement in a particular space and regulate lighting and heating automatically. 
Persa FOKIALI, Rezan TATLIDIL,

Loukas MOUSTAKAS and Yota XANTHAKOU

Other infrastructure work and the layout of the surrounding area include the necessary interventions to connect the Environmental Workshop to public utility networks and the landscaping of outdoor areas and the campsite, as follows:

- Connection to the national grid of the Public Power Corporation (PPC)

- Connection to the Telecommunications Organisation network with an ISDN line

- $\quad$ Connection to ADSL network

- Installation of telephones for use with the Telecommunications Organisation cards

- Connection to the water supply

- Provision of parking spaces for approximately 15 vehicles, involving the asphalting of an area of $400 \mathrm{~m}^{2}$

- Landscaping of surrounding area to render it suitable for lessons outdoors, when weather permits

- Landscaping of campsite area ${ }^{11}$.

As shown in Table 2, expenditure for the special works required infrastructure work and landscaping of the surrounding area.

Table 2: Special Works, Infrastructure Work and Landscaping Of Surrounding Area

\begin{tabular}{|l|r|}
\hline \multicolumn{1}{|c|}{ TYPE OF WORK } & COST \\
\hline PHOTOVOLTAIC SYSTEM & 79,600 \\
\hline AUTOMATED SMART STRUCTURE SYSTEM & 20,000 \\
\hline CONNECTION TO NATIONAL ELECTRICITY GRID (PPC) & 2,000 \\
\hline CONNECTION TO NATIONAL TELECOMMUNICATIONS NETWORK & 200 \\
\hline GTO) & 600 \\
\hline CONNECTION TO INTERNET ADSL 24 MbPS & 700 \\
\hline INSTALLATION OF TELEPHONES FOR USE WITH GTO CARDS & 500 \\
\hline CONNECTION TO MAINS WATER SUPPLY & 3,000 \\
\hline ASPHALTING OF PARKING AREA & 1,500 \\
\hline LANDSCAPING OF SURROUNDING AREA & 108,100 \\
\hline TOTAL
\end{tabular}

\section{Machinery and Equipment}

The equipment needed for the MCSD can be divided into four categories, namely: furniture, electronic appliances, laboratory equipment and books.

As shown in Table 3 the cost of equipping the Workshop is set out. 
TECHNO-ECONOMICAPPROACHES TO ENVIRONMENTALACTIONS: A CASE STUDY FOR THE ESTABLISHMENT OF A CENTRE FOR SUSTAINABLE DEVELOPMENT IN THE ISLAND OF RHODES

Table 3 : Equipment

\begin{tabular}{|c|c|}
\hline TYPE & COST \\
\hline FIRE SAFETY & 4,000 \\
\hline LIGHTNING CONDUCTORS & 1,500 \\
\hline $\begin{array}{l}\text { HEATING \& AIR CONDITIONING } \\
(4 \times 900)+(3 \times 600)\end{array}$ & 5,400 \\
\hline FANS & 500 \\
\hline SOLAR WATER HEATERS & 1,500 \\
\hline ELECTRICAL APPLIANCES & 20,000 \\
\hline LABORATORY EQUIPMENT & 11,000 \\
\hline FURNITURE & 15,500 \\
\hline BOOKS $(1,000)$ & 20,000 \\
\hline TOTAL EQUIPMENT EXPENDITURE & 79,400 \\
\hline
\end{tabular}

\section{Total Budget}

As shown in Table 4, the overall budget for the project is 294,300 Euro.

Table 4: Total Budget per Category of Expenditure

$$
\text { CATEGORY OF EXPENDITURE }
$$

COST

106,800

108,100

SPECIAL WORKS, INFRASTRUCTURE WORK AND LANDSCAPING

COMPUTERS, etc.

294,300

\section{Financing and Investment Timetable}

It is proposed that the financing of the project should be met from private capital, loans and a small grant for the cost of installing renewable energy resources.

The investment plan is expected to be completed within seven months from the date construction work starts.

\subsubsection{Viability Forecast}

\section{Anticipated costs}

The human resources that are expected to meet the goals of the MCSD comprise an inter-disciplinary team of four specialists, with the aim of covering as broad a scientific spectrum as possible, namely: 
Persa FOKIALI, Rezan TATLIDIL,

Loukas MOUSTAKAS and Yota XANTHAKOU

- An instructor with a postgraduate degree in Environmental Education who will head up the team, since the MCSD's primary mission is to provide environmental education of an "informal" nature;

- Anenvironmentalist with a degree from a university or technical college, who will use his specialised knowledge and expertise in any environmental issues that may crop up and also act as an advisor to members of the local community;

- A biologist who will be able to throw light on questions of interaction and interdependence amongst living and non-living things;

- A physicist to carry out the laboratory work, with particular regard to energy-related issues;

- Two school-leavers with a good knowledge of IT, which will provide support for the MCSD's other staff and help with the secretarial work.

In an effort to keep, operating costs down, the above employees will be responsible for the operation of the MCSD's various sections. Details of expenses are set out in the table below.

Scientists and other experts, whenever possible from within the local community, will be invited to give talks on various environmental matters to provide an integrated approach to problems and issues. Other municipal employees will also be asked to offer their services (cleaning, maintenance, repairs, etc.) to the MCSD in order to peg costs at a reasonable level.

As shown in Table 5, expenditure is set out according to category.

Since this project is a matter of priority for the Municipality, the costs of both constructing and operating the MCSD will be met by it as part of its environmental policy.

\section{Anticipated benefit}

Measuring the benefits of such a MCSD is not an easy task. Given that the MCSD is not going to sell its services, there are no earnings in money terms. One could question why the MCSD does not apply a profit-making policy with regard to its visitors and the users of its services. However, the targets of the MCSD make such a policy inappropriate. A profit making policy would act negatively on the number of visitors and users while the aim is to attract as large as possible a section of the local population to the MCSD. Only when a large number of people is attracted, the level of environmental awareness will increase and the MCSD will contribute to improving the state of the environment in Greece. Under such circumstances, the only sources of earnings in money terms are derived from selling electricity to the Public Power Company (PPC) and, possibly, educational material to interested bodies and organisations. 
TECHNO-ECONOMIC APPROACHES TO ENVIRONMENTAL ACTIONS: A CASE STUDY FOR THE ESTABLISHMENT OF A

However, the amount from such transactions is expected to be limited and to cover an almost negligible part of total cost.

Table 5: Predicted Cost In A Typical Year Of Operation

\begin{tabular}{|l|r|r|}
\hline & Per month & Per year \\
\hline Wages and salaries (total) & 10000 & 140000 \\
\hline Remuneration of external associates & 2000 & 24000 \\
\hline Staff training & 200 & 2400 \\
\hline Staff travelling expenses & 200 & 2400 \\
\hline Subscriptions/ books & 200 & 2400 \\
\hline Production of teaching material & 300 & 3600 \\
\hline Receptions/ Special events/ conferences & 500 & 6000 \\
\hline Telephone bills, electricity bills, water bills & 400 & 4800 \\
\hline Stationery, etc. & 300 & 3600 \\
\hline Computer consumables & 200 & 2400 \\
\hline Laboratory consumables & 200 & 2400 \\
\hline Equipment maintenance \& repair & 200 & 2400 \\
\hline Cleaning materials & 200 & 2400 \\
\hline Advertising \& public relations & 300 & 3600 \\
\hline Loan repayments & 1200 & 14400 \\
\hline Depreciation & 981 & 11772 \\
\hline TOTAL & 1 & 216800 \\
\hline
\end{tabular}

However, there is several important social benefits derived form the operation of the Centre. Although their quantification goes beyond the scope of this study, one can mention indicatively some of them that are decisive for the MCDS contribution to the to the society's welfare. Thus:

- Environmental awareness is expected to lead in the long run to a cleaner environment hence also to a better state of health for local citizens, less medical expenses, less absences from the jobs, hence higher productivity of the local economy ${ }^{12}$.

- Moreover, the upgrading of the environment because of an environmentally educated population is expected to make the area more attractive to tourists and day visitors. In such a case, local production is expected to stimulate and prices of local goods and 
Persa FOKIALI, Rezan TATLIDIL,

Loukas MOUSTAKAS and Yota XANTHAKOU

services are going to become more competitive. It is estimated that if each tourist staying overnight in the area increases his/her expenses by a little less than 1 euro $(0,94$ euros) , this is adequate to bring to the society gross revenues that balance the operation cost of the $\operatorname{MCSD}^{13}$. This estimation is made, under some strict assumptions, such as a constant number of tourists arrivals and overnight staying in the area, a short season of tourism (not exceeding 120 days), a moderate vacancy rate $(30 \%)$ in hotels and without taking into account some extra expenses that day visitors to the MCSD and the area are expected to make.

\section{Final decisions}

From the techno-economic approach described above it is concluded that the project is feasible and worth implementing, particularly due to its contribution in sustainable development.

Its viability is grounded on the important nature of the mission it is called on to perform, namely to endeavour to protect the country's rich natural assets and to render members of the public more aware of environmental issues, with a view to changing their attitudes towards the environment and stimulating them to take action.

\section{CONCLUSION}

Overall, the above analysis has shown that the techno-economic study is an adequate tool for making an integrated approach to actions/investment/projects of environmental content. No one denies that in order to have successful results, appropriate adjustments should be made so that this business-oriented tool is suitably adapted to the specific needs of environmental actions. However, this study has also shown that these adjustments are not big and that the techno-economic approach is adequate without requiring major deviations from the specifications, conventions and standard forms on which it is based in the case of business-oriented applications.

It is true that for a successful implementation of a sustainable development strategy, the relevant actions, projects, investments and plans must be widely accepted by all societal groups involved in the development processparticularly by the business world, which utilizes input from the environment for production purposes and is the one that is considered responsible for increasing environmental threatens. It is easier for business agents to adopt sustainable development practices and to accept any sustainable development strategy if the sustainable development plans are based on methodological tools that they understand and if these plans employ terms, codes and mechanisms with which the agents are familiar in everyday practice. One of the major comparative advantages of applying techno-economic approaches in environmental 
TECHNO-ECONOMIC APPROACHES TO ENVIRONMENTAL ACTIONS: A CASE STUDY FOR THE ESTABLISHMENT OF A CENT'RE FOR SUSTAINABLE DEVELOPMENT IN T'HE ISLAND OF RHODES decision-making is that such approaches help communication among the different participants of the development process.

\section{ENDNOTES}

(1) Analysis was carried out of the original texts of a full Feasibility Study on behalf of Reading Memorial High School (Gene, 2000).

(2) It should be noted here that bibliographic research on this subject is very difficult, for two main reasons. Firstly, the number of books written specifically about such studies is very small and generally speaking the bibliography makes only occasional reference to them. Secondly, writers of international articles tend to restrict themselves to announcing the results of their research, without presenting any procedural details that might give information about the structure of the studies themselves; examples of this phenomenon are provided by the following publications: Farrell \& Wang (2005), Skourou, Hoopes, Strawbridge \& Paulsen (2004) and Wiedemann, Clauberg, Kargen \& Henseler (2005).

(3) Certain sectors may not adhere to this particular model but may use a modified version according to the needs of each sector.

(4) This approach refers to the group of conceptual dualities in environmental ethics, in which contrasting views are presented regarding the manner in which we perceive the natural environment (Georgopoulos, 2002, Norton, 1987).

(5) However important market analyses may be, they cannot course, predict all eventualities, such as "new entries" to the market (Cooper \& Ebin, 2004ab).

(6) With regard to the product, important factors are the quality, plan, packaging, guarantee, and possibility of return, sales and after-sales service in general. Price includes reductions, credit sales and all the relevant agreements. Promotion entails advertising, public relations, sales promotions and brand policy. The last of the four principles, place, concerns distribution, delivery times, stocks and transportation.

(7) Data about the Municipality was obtained in May 2005 from the Programming \& Planning Office and from the General Development Plan for the Municipality of Petaloudes, which was drawn up in 2000 by town planner Stavros Tsetsis.

(8) The PPC power station is situated near Petaloudes, but because of the prevailing northeasterly winds in the area, emissions affect mainlythe Municipality of Petaloudes that lies to the southeast of the plant.

(9) The minutes of the Tbilisi Conference define the basic characteristics of the ongoing nature of Environmental Education as its problem-solving orientation, 
Persa FOKIALI, Rezan TATLIDIL,

Loukas MOUSTAKAS and Yota XANTHAKOU

its interdisciplinary approach and the incorporation of such education into the local community.

(10) It should be noted that the total budget as well as the cost of each category and sub-category of expenditure are in euros and were derived after a short investigation of the market prices of the relevant items in 2006. They are reported here exclusively for presentation purposes and as an exercise that indicates the mechanism of approaching a total budget. Accurate prices may deviate substantially from those reported here.

(11) This is tabled merely as an idea at this stage, in order to present a complete picture of the goals of the Environmental Workshop. Since the matter is beyond the remit of this study, no further analysis is carried out here.

(12) It may be estimated that if $15 \%$ of the local population reduces the number of visits to medical centres by one per year , this will save $\left(12133^{*} 0,15^{*} 30\right.$ euros) 54599 euros, which is equivalent to $24 \%$ of the total cost of the MCSD's operation.

(13) This is estimated as follows:

Number of tourist beds in the area

2896

Length of tourist season (days)

Full to capacity

Estimated no. of tourists overnight staying $(A)$

243264

Anticipated cost of operation (B), in euros

228572

B/A (=euros/tourist)

0,94

\section{REFERENCES}

BEGG, D. (1998). Introduction to Economics, Vol. I \& II. Athens: Kritiki.

BURKE, R. (2002). Project Management. Planning \& control techniques. Athens: Kritiki.

COOPER, H. \& Ebin, L. (2004). What to look for in a project feasibility study Part 1. Hydrocarb process, 83, No. 8.

COOPER, H. \& Ebin, L. (2004, September). What to look for in a project feasibility study - Part 2. Hydrocarb process, 83 No. 9.

DUNCAN, W. (1996). A Guide to the Project Management Body of Knowledge (PMBOK). Pennsylvania: PMI. 
TECHNO-ECONOMICAPPROACHES TO ENVIRONMENTALACTIONS:

A CASE STUDY FOR THE ESTABLISHMENT OF A

CENTRE FOR SUSTAINABLE DEVELOPMENT IN THE ISLAND OF RHODES

FARRELL, J. \& Wang, J. (2005). Feasibility Study for reductive of carbon tetrachloride using bare and polymer coated nickel electrodes. Journal of Applied Electrochemistry, Vol. 35, 243-248.

GENE, R. (2000). Feasibility Study for Reading Memorial High School. Hingham: Strekalovsky \& Hoit.

GEORGOPOULOS, A. (2002). Environmental Ethics. Athens: Gutenberg, in Greek.

GYPTON, C. \& Shillabeer, J. (2003, September). Mining risk management conference. Sydney NSW, 9-12.

GYPTON, C. (2002). How have we done? Feasibility Performance since 1980. Engineering and Mining Journal, No.1, 203.

HANFORD, L. (1972). Feasibility Study Guidelines. Chicago: Institute of Real Estate Management.

HELDMAN, K. (2003). Project Management Jump Start. USA: Sybex

HELDMAN, K. (2004). PMP Project Management Professional. USA: Sybex.

KARVOUNIS S. (2000). Techno-Economic Studies. Athens: A Stamoulis. In Greek.

KARVOUNIS, S. (2002). Techno-Economic Studies. Specimen studies. Case Studies. Problems and exercises. Athens: A. Stamoulis. in Greek.

KOTLER, P. (2005). Principles of Marketing. Great Britain: FT Prentice Hall.

LEWIS, J. (1998). Mastering Project Management. New York: McGraw-Hill.

MEREDITH, J. \& Samuel. J. (1995). Project Management. A managerial approach. USA: Wiley.

MILIOTI, E. (1992). Techno-Economic Studies. Athens: Synchroni Ekdotiki, in Greek.

NORTON, B.G. (1987). Environmental Ethics and Nonhuman Rights, Environmental Ethics, 4.

SKOUROU, C., Hoopes, J., Strawbridge, R. \& Paulsen, K. (2004, February). Feasibility Studies of electrical impedance spectroscopy for early tumor detection in rats. Institute of Physics Publishing/Physiological Measurement, 25, 335-346. 
Persa FOKIALI, Rezan TATLIDIL,

Loukas MOUSTAKAS and Yota XANTHAKOU

WIEDEMANN, P., Clauberg, M., Kargen, C. \& Henseler, G. (2005). Application of early risk detection concepts and methods to environmental health. A German feasibility study. Journal of Risk Research, Vol. 8 (6), 513-529. 